\title{
Viewing Development Through the Lens of Culture: Integrating Developmental and Cultural Psychology to Better Understand Cognition and Behavior
}

Perspectives on Psychological Science 2022, Vol. 17(1) 62-77 (C) The Author(s) 2021 Article reuse guidelines: sagepub.com/journals-permissions DOI: $10.1177 / 1745691620980725$ www.psychologicalscience.org/PPS (9SAGE

\section{Larisa Heiphetz ${ }^{1}$ and Shigehiro Oishi ${ }^{2}$}

${ }^{1}$ Department of Psychology, Columbia University, and ${ }^{2}$ Department of Psychology, University of Virginia

\begin{abstract}
Although many definitions of culture exist, studies in psychology typically conceptualize different cultures as different countries. In this article, we argue that cultural psychology also provides a useful lens through which to view developmental milestones. Like other forms of culture, different developmental milestones are demarcated by shared values and language as well as transmission of particular social norms. Viewing development through the lens of cultural psychology sheds light on questions of particular interest to cultural psychologists, such as those concerning the emergence of new cultures and the role of culture in shaping psychological processes. This novel framework also clarifies topics of particular interest to developmental psychology, such as conflict between individuals at different milestones (e.g., arguments between older and younger siblings) and age-related changes in cognition and behavior.
\end{abstract}

\section{Keywords}

culture, development, social cognition

The movie Boyhood (Linklater, 2014) follows Mason Evans, Jr., from age 6 to adulthood. This film captures many developmental milestones, including the elementary school years, adolescence, and the transition to adulthood. As viewers watch Mason grow, they may also be observing cultural changes. In other words, frameworks from cultural psychology can help shed light on transitions such as that between childhood and adolescence.

In this article, we argue for the integration of cultural psychology (the study of how and why psychological processes change or stay the same across different cultures) and developmental psychology (the study of how and why psychological processes change or stay the same across age). Researchers have conceptualized culture largely in terms of nations, with different nations having different cultures (Gelfand et al., 2011; Hofstede, 1980; Schwartz et al., 2012; Triandis, 1995). We present the novel argument that developmental milestones function similarly to cultures in important ways and that understanding such milestones through an integration of cultural and developmental psychology may be more informative than using frameworks from either subdiscipline alone. This view clarifies topics commonly studied in cultural psychology, such as how cultures emerge and how they shape psychological processes, and those commonly studied in developmental psychology, such as cross-age conflict as well as changes in cognition and behavior across age.

\section{What Is Culture?}

As discussed above, psychologists have commonly described culture in terms of nations, although scholars in disciplines such as business (e.g., Taras et al., 2016) have pointed out that the two terms are not synonymous. Some work has also included groups according to race, religion, socioeconomic status, and political affiliation (A. B. Cohen, 2009; Haidt, 2013; Oyserman et al., 1995; Stephens et al., 2014). Twenge and colleagues (e.g., Twenge et al., 2012) have conceptualized cohort as a form of culture. However, the idea that

\section{Corresponding Author:}

Larisa Heiphetz, Department of Psychology, Columbia University

E-mail: lah2201@columbia.edu 
generations (groups of people born at approximately the same time) constitute culture differs from the current proposal that developmental milestones function similarly to cultural groups because people remain in the same generational cohort their entire lives while moving from one developmental milestone to another. Thus, some aspects of cultural psychology (e.g., work on moving from one culture to another) are particularly relevant to developmental milestones. Regardless of which groups are included, they should generally possess shared values and language in addition to shared geography to be considered a culture (Triandis, 1995; see also Schwartz, 1992).

Defining culture in terms of groups such as nations is appealing for several reasons: It is straightforward (boundaries between different nations are often clearcut, so it is obvious whether one is talking about, say, Japan or Canada) and allows scholars to compare their research with prior work, which has also typically conceptualized culture in terms of countries. However, this type of definition contains some difficulties (Heine, 2016; Oyserman, 2017). Boundaries between different cultural groups are not always as distinct as boundaries between nations. People from different countries can communicate with and learn from each other, and cultural norms can therefore spread across groups (Kashima, 2000). Furthermore, the diverse experiences of individuals within a culture can create intracultural variability. The United States is more culturally homogeneous than many other countries (Muthukrishna et al., 2020). However, even this country shows some degree of cultural heterogeneity. For instance, although cultural psychologists typically portray the United States as an individualistic culture (e.g., Markus \& Kitayama, 1991), some U.S. residents may nonetheless adopt collectivist frameworks (e.g., Snibbe \& Markus, 2005; Vandello \& Cohen, 1999). In addition, the degree of individualism in the United States has changed over time (Greenfield, 2013; Varnum \& Grossmann, 2017).

Instead of defining culture as broadly construed, some scholars have delineated particular elements of culture. For example, Hofstede's (1980) cultural dimensions theory proposed several axes along which cultures could differ, including social hierarchy strength and masculinity-femininity. Somewhat similarly, Schwartz (1992) proposed a system of basic human values that exist across diverse cultures, such as openness to change and self-transcendence. Recently, Gelfand and colleagues (2011; Harrington \& Gelfand, 2014) proposed the additional dimension of tightnesslooseness, corresponding to the strength of social norms and tolerance for deviant behavior in a culture. Likewise, several scholars have proposed relational mobility (the ease with which individuals can form new relationships and exit undesirable relationships) as a major dimension of culture and have shown that this factor explains cross-national differences in trust and intimacy (Thompson et al., 2018; Yuki \& Schug, 2012).

When delineating aspects of culture, psychology has largely focused on individualism and collectivism. This distinction occurs both in cultural dimensions theory, which includes a dimension for these factors, and in the theory of basic human values, which posits that values such as self-enhancement may exist across cultures. Numerous studies have shown that different cultures place different levels of emphasis on individualism compared with collectivism and that these differences play a role in other aspects of cognition and behavior, such as emotional experience and views of relationships (Markus \& Kitayama, 1991; Oishi \& Komiya, 2017; Oyserman \& Lee, 2008; Triandis, 1995).

Some work focusing on facets of culture has addressed concerns around defining cultures as groups with sharp boundaries. For instance, the culture-assituated-cognition framework (Oyserman, 2017) highlights situations, rather than only groups, that make specific facets of culture particularly accessible. As one example, people in Western and Eastern cultures can view the world through an individualistic lens, and people in both cultures can also adopt collectivist perspectives. However, the extent to which each facet is accessible varies across countries. Thus, collectivism emerges more commonly in Eastern rather than Western settings because collectivist construals are made particularly accessible, but specific situations (e.g., being surrounded by one's family vs. by competitors) can make either of these facets salient across nations. The culture-as-situated-cognition framework also applies to cultural groups other than nations. For instance, Black and White children in the United States receive different cultural teachings regarding racism (Hughes et al., 2006; Perry et al., 2019). These teachings shape the frameworks that are readily accessible when children evaluate themselves (Oyserman et al., 1995) and when perceivers respond to children of different races (Goff et al., 2014; Okonofua \& Eberhardt, 2015).

Perhaps of greatest relevance to the current work, scholars beyond psychology have written about peer cultures (e.g., sociologists, Corsaro \& Eder, 1990; anthropologists, Schlegel, 2000). This work has focused largely on describing the norms of particular cultures. For instance, work on peer cultures has investigated how preschoolers in the United States and Italy manage conflict (Corsaro \& Rizzo, 1990), how children in the United Kingdom play with each other (Opie \& Opie, 1969), and how Israeli children interact with peers (Katriel, 1988/1989). Building on this ethnographic approach, we highlight how cultural psychology and 
developmental psychology can come together to elucidate cognition and behavior. For instance, a detailed observation of a particular school can highlight how conflict occurs (e.g., who says what to whom). Integrating cultural and developmental psychology can provide novel insight into why this conflict occurs (e.g., one underlying mechanism could be children's more individualistic culture vs. older adults' more collectivist culture; see the section, Questions Concerning the Ways in Which Developmental Differences Mirror Cultural Differences) and what strategies might reduce such conflict (e.g., students in different grades could complete cooperative activities together, which may reduce conflict among members of different grades; see the section, Questions Concerning Conflict Between Individuals at Different Milestones).

The perspectives discussed so far have adopted a descriptive approach. In other words, the theories highlighted thus far have sought to characterize particular features of different cultures, including the extent to which they vary along dimensions such as collectivismindividualism. Another approach in cultural psychology seeks to clarify the origins of culture. These approaches are another way of addressing concerns with describing cultures in terms of nations or other groups. Rather than emphasizing the fuzziness of the boundaries among groups, origin theories view culture as a social process through which people transmit knowledge to each other (Boyd \& Richerson, 2005), teach each other rules that ensure a group's survival (Matsumoto, 1990), or develop a set of patterns governing behavior (Adams \& Markus, 2001; Kroeber \& Kluckhohn, 1952). These definitions highlight culture as a verb (e.g., transmitting and learning social norms) rather than a noun (e.g., Americans, Protestants) and ask how cultures came to be rather than emphasizing the current features of those cultures, as descriptive theories do.

The social component of knowledge transmission is crucial; as Linton (1936) pointed out, cultures include "social heredity" as opposed to "biological heredity." According to this view, cultural transmission includes social learning as opposed to changes that can occur without social input, such as growing taller. Such social learning typically includes intergenerational transfer, with members of older generations teaching members of younger generations important information (e.g., Boyd \& Richerson, 2005). Such learning can happen in formal institutions such as schools, a process that is particularly common in Western, industrialized, rich, democratic nations (Scribner \& Cole, 1973). Such learning can also happen in less formal environments, such as parents teaching children what is safe to eat by selecting some available items but not other items for consumption (van Schaik, 2010). Both of these examples highlight vertical transmission from older to younger generations, but such transmission can also happen horizontally among members of the same generation, such as when a group of children teach each other norms via playground games (Opie \& Opie, 1969; for additional discussion regarding vertical and horizontal transmission, see Henrich \& Gil-White, 2001). Indeed, informal transmission is particularly common when peers teach each other because they tend to engage in collaborative learning rather than formal instruction (Wood \& O'Malley, 1996).

The context in which learning occurs has implications for psychological processes. For example, some developmental milestones described by Piaget (e.g., reasoning that a quantity would remain the same regardless of the size or shape of its container) appear cross-culturally among formally schooled children but not among children who have not received education via formal systems (Bruner et al., 1966). Such differences are to be expected given that developmental psychologists created many tasks in the context of Western environments that include formal education.

In sum, descriptive theories have often defined culture in terms of groups, particularly nations. However, some scholars have expanded this definition to include other groups (e.g., religious, political) and to highlight the role of social processes. Recent work has extended definitions of culture by focusing on particular elements that distinguish one culture from another, such as collectivism-individualism, tightness-looseness, and relational mobility. Additional work on origins has emphasized questions regarding how cultures came to be the way they are, complementing the more descriptive approaches outlined above. However, past work in psychology has not emphasized similarities between developmental milestones and other forms of culture, and work from other disciplines on peer cultures has focused largely on describing particular social groups (e.g., a group of Italian preschoolers). Building on this approach, we consider how the ways of conceptualizing culture reviewed here may apply to development and how integrating cultural and developmental psychology leads to new insights that move beyond describing social processes among members of a particular culture.

\section{How Are Developmental Milestones Similar to Other Forms of Culture?}

As discussed above, researchers have described culture in terms of groups (e.g., nations, religions) and asked about the processes that give rise to particular cultures (e.g., transmitting social information, learning social norms). Like other forms of culture, developmental 
Table 1. Definitions of Culture With Examples From Development and Other Forms of Culture

\begin{tabular}{|c|c|c|}
\hline Definition & Examples from development & $\begin{array}{l}\text { Examples from cultures as typically } \\
\text { conceived in cultural psychology }\end{array}$ \\
\hline $\begin{array}{l}\text { Culture as a noun (different } \\
\text { groups constitute cultures) }\end{array}$ & Day-care centers, assisted-living communities & $\begin{array}{l}\text { Countries, religious groups, groups } \\
\text { demarcated by socioeconomic status }\end{array}$ \\
\hline $\begin{array}{l}\text { Groups have shared } \\
\text { values }\end{array}$ & $\begin{array}{l}\text { Erikson's model of development focusing on } \\
\text { different values of importance at different } \\
\text { developmental milestones (e.g., autonomy } \\
\text { vs. shame and doubt for toddlers; integrity } \\
\text { vs. despair for older adults) }\end{array}$ & $\begin{array}{l}\text { Collectivism-individualism; tightness- } \\
\text { looseness }\end{array}$ \\
\hline $\begin{array}{l}\text { Groups have shared } \\
\text { language }\end{array}$ & Slang that is common among adolescents & $\begin{array}{l}\text { Swahili, Spanish, Arabic; words with } \\
\text { particular meanings within certain groups } \\
\text { (e.g., communion for Catholics) }\end{array}$ \\
\hline $\begin{array}{l}\text { Groups have shared } \\
\text { rules and norms }\end{array}$ & $\begin{array}{l}\text { Following established guidelines (toddlers); } \\
\text { seeking one's own way independently } \\
\text { of established guidelines (adolescents, } \\
\text { particularly in the United States) }\end{array}$ & $\begin{array}{l}\text { Saying the pledge of allegiance; kneeling to } \\
\text { pray; sharing one's resources }\end{array}$ \\
\hline
\end{tabular}

milestones meet these definitions (Table 1). Therefore, integrating cultural and developmental psychology can provide a useful lens through which to view such milestones.

A developmental milestone is a particular pattern of cognition or behavior that most people demonstrate by a particular age. For instance, many children take their first physical steps around their first birthday. The preschool and early elementary school years constitute a different kind of milestone, when many begin to take their first steps toward orienting their social lives around peers rather than only family (although family remains important, it no longer constitutes children's only social sphere as they enter school). By convention, developmental psychologists have demarcated common milestones as including infancy, toddlerhood (approximately 2-4 years), early childhood (approximately 5-8 years), middle childhood (approximately 9-12 years), adolescence (approximately 13-18 years), early adulthood (through one's 40s), middle adulthood (through one's 60s), and late adulthood (until the end of life). Individuals in a given milestone may differ from each other (e.g., 4-year-olds typically walk better than 2-year-olds), but they also share many characteristics (e.g., toddlers as a group are worse than older individuals at attributing false beliefs to others and have different relationships with their parents than do individuals at earlier and later milestones). Developmental psychology focuses largely on Western, educated, industrialized, rich, and democratic countries, particularly the United States (Nielsen et al., 2017). Other cultures may demarcate milestones differently; however, these differences have not yet permeated much developmental research.

Historically, developmental psychology has been particularly interested in describing the stages through which children must pass to achieve particular outcomes, such as adult-like moral reasoning (Kohlberg et al., 1983) or cognitive abilities (Piaget \& Inhelder, 1969). Modern developmental psychology has largely moved away from a focus on stage theories but nevertheless attends to important developmental milestones. For instance, rather than theorizing about which stages of moral development children pass through at which ages, recent scholarship regarding the emergence of moral cognition has shown evidence of moral judgments at earlier milestones than previously thought (i.e., among infants; Hamlin, 2013) and has demonstrated different moral judgments among children who have passed particular milestones compared with children who have not passed those milestones (e.g., different moral evaluations among children who were vs. were not able to accurately attribute mental states to others; Killen et al., 2011).

It is easy to see how developmental milestones fit the descriptive perspective that different groups reflect different cultures with their own norms and traditions. Many countries currently group people according to developmental milestones. For instance, in Western cultures such as the United States, day-care facilities separate infants from toddlers, elementary schoolers learn in different classrooms than high schoolers, and retirement-community residents cohabitate because of their common age. However, such groupings are not 
universal; for example, cultures vary in the extent to which elders live separately from other family members (Georgas et al., 2006) and the extent to which children participate in formal education that divides them into groups on the basis of developmental milestones (Scribner \& Cole, 1973).

Furthermore, several scholars (e.g., Gelfand et al., 2011; Hofstede, 1980; Markus \& Kitayama, 1991; Schwartz, 1992) have pointed out that cultures are not simply discrete groups; rather, they may arise from a set of processes and reflect characteristics that both vary along a continuum. The developments that mark different milestones are often similarly continuous. For instance, much work in developmental psychology has focused on theory of mind-the ability to accurately attribute mental states such as beliefs, knowledge, and desires to others (e.g., Wimmer \& Perner, 1983). Children begin passing standard theory-of-mind tasks around the age of 5 years (Wellman et al., 2001). However, it is not the case that children have no concept of others' minds the day before their fifth birthday and a perfect concept of these minds the day after. Infants may have some semblance of theory of mind (e.g., Onishi \& Baillargeon, 2005), children develop first-order theory-of-mind skills (the ability to accurately infer what Person A thinks) before developing second-order skills (the ability to accurately infer what Person A thinks about Person B's mental states; Miller, 2009), and even adults do not always demonstrate perfect theory of mind (e.g., Keysar et al., 2003). Theory-of-mind development is also continuous across culture. Some aspects of this ability appear consistent across different environments. For instance, children begin passing standard tasks asking them to make inferences about one other person's mental states around their fifth birthday in multiple cultures, including Canada, India, Peru, Samoa, and Thailand (Callaghan et al., 2005).

However, some scholars (e.g., Greenfield et al., 2003) have argued that theory-of-mind models originated in and best describe development that occurs in individualistic cultures. Inferences regarding others' mental states depend on distinguishing one's own mind from another person's mind, a task that inherently emphasizes individual minds. From this perspective, the more collectivist a particular culture is, the less appropriate standard measures of theory of mind become. This view accords well with cultural psychology. For instance, Hofstede (1980) described cultures as varying along an individualism-collectivism dimension with scores ranging from 0 (high collectivism) to 100 (high individualism). Cultural psychology research may compare two cultures that vary in the degree to which they exhibit individualism or collectivism, but this is not a binary distinction.
In addition to these similarities between culture and developmental milestones, such milestones also come with another hallmark of culture- "shared values and language" (Triandis, 1995). One early model of shared values comes from developmental psychology, in which Erikson (1956) viewed development as a progression through different sets of values. According to this model, infants must determine whether to trust or mistrust their environment, toddlers develop the value of autonomy (if caregivers provide a safe basis for exploration) or experience shame and doubt (if caregivers treat the child's growing independence with ridicule, severe constraints, or other negative responses), and so on through old age, at which point people face the life they have lived and experience a sense of contentment if this life conforms to their values and despair if it does not. In this model, developing a life that is consistent with a particular value is a central focus during a specific developmental time point but becomes an area of less emphasis at other times, although it may not disappear entirely. For instance, toddlers share the development of autonomy with other toddlers, but this value is less relevant to senior citizens who have successfully navigated childhood. In terms of shared language, people at similar points of development sometimes use terms that are less common among or do not make sense to people at other points. For instance, adolescents in a variety of places-including Brazil, France, the United States, and the United Kingdom-use slang to develop connections with other adolescents, although these ways of speaking may not make sense to individuals at other developmental milestones (Eckert, 2003). As another example, elders in South Africa sometimes engage in "complaint discourse" as a way to manage their age-related social identity; for instance, complaints about disrespect can reinforce the importance of social norms regarding respect for one's elders (Sagner, 2017).

A focus on shared rules and norms in particular groups (e.g., Adams \& Markus, 2001; Kroeber \& Kluckhohn, 1952; Matsumoto, 1990) provides another aspect of cultural psychology that can offer a useful lens through which to view developmental milestones. Young children place a great deal of emphasis on following rules and norms even though they can appreciate that different norms apply to different groups of people. German preschoolers readily infer the presence of social norms (Schmidt et al., 2016) and object when others violate these norms (Koymen et al., 2014). Furthermore, preschoolers in Western cultures prefer people who follow the same social norms as themselves (Heiphetz, 2017) and learn more readily from conformists than from nonconformists (Corriveau et al., 2009). In contrast, adolescents in the United States often emphasize 
independence and autonomy (Greenfield et al., 2003; Stewart et al., 1999). As another example, adolescents typically value exploration and encourage each other to try new things (Brown et al., 1986; Kracke, 2002). However, by adulthood, Westerners who have not established stability in areas of life such as romantic relationships face negative judgment (DePaulo \& Morris, 2006). In other words, the rules and norms that govern behavior change across development.

If, instead, one adopts a more origin-based view of culture and emphasizes the emergence of culture from the transmission of social information, it is again relatively straightforward to see how developmental milestones might fit. Simply being a particular age is a matter of biology, but learning and performing the practices associated with particular developmental milestones is a social matter. In fact, social practices often demarcate development in addition to-and sometimes more than-one's date of birth. For instance, in the United States, people may perceive a 40 -year-old businessman who lives with his wife and two children as being more developmentally advanced than a single 40-year-old man who is unemployed and lives in his parents' basement even though both men are the same age. The businessman has achieved more markers of adulthood prominent in Western cultures (e.g., steady employment, parenthood) and may therefore be perceived as being at a later developmental milestone than the unemployed man despite their similar biological age. Work that focuses on the origins and transmission of cultural practices can therefore shed light on developmental milestones. A cultural psychology perspective emphasizing the transmission of social norms can clarify why two people who are the same age can nevertheless be at different developmental milestones. In the example above, the two 40-year-old men engage in different cultural practices that they have learned in different ways. The businessman might wear expensive suits, arrive to work on time, and make small talk with his colleagues because he has observed coworkers modeling these behaviors. The unemployed man is unlikely to have current exposure to such cues or find himself in an environment where they matter. In other words, his culture is not transmitting to him the message that it is important to wake up early and wear expensive clothes, so he may be less likely to engage in such practices.

Psychologists often reference maturation to explain differences across different age groups. For instance, differences between a toddler and an adolescent can arise from social, cognitive, and neural factors that have matured over a decade of life (Tottenham, 2020). Such explanations are undoubtedly correct and greatly enhance scientific understanding of what changes across development. The purpose of this article is not to argue that a cultural psychology framework should supplant these maturation approaches. Rather, we seek to offer a complementary perspective that can further clarify development. Specifically, we argue that in addition to maturation, age-related differences can also be viewed through the lens of culture and cultural learning. Adopting this view benefits both developmental and cultural psychology, as outlined in the sections below.

Cultural transmission begins to occur well before adulthood. Young children are already adept at social learning, imitating adults even when their practices are inefficient (Gergely et al., 2002; Legare \& Nielsen, 2015). As people develop, they may begin to learn from older individuals who are similarly situated in terms of developmental milestones in addition to learning from people at different developmental points. For example, in one study in which adolescent siblings between 13 and 17 years old were tested, the younger sibling was more likely to smoke if the older sibling smoked, but the behavior of younger siblings did not influence older siblings (Harakeh et al., 2007). Likewise, having an older sibling become an adolescent mother increases the risk that younger female siblings will engage in early sexual activity and become pregnant early in life (East, 1998). Consistent with theories that people are especially likely to learn cultural practices from others who are high in prestige (Henrich \& Gil-White, 2001), popular group members exert more social influence than less popular members (Chudek et al., 2011; Laursen et al., 2012).

Of course, people move from one developmental milestone to another in the context of other cultural groups. Important prior work has highlighted how national culture can shape development. For instance, children growing up in a Western society distributed more resources to individuals who were more successful at a particular task (using a magnet to retrieve cubes out of a container), whereas children in a pastoralist African society did not consider task success when distributing resources (Schafer et al., 2015). Culture can also shape children's experiences with their caregivers. For instance, caregivers in the United States teach children actively, using strategies such as guiding children's behaviors and offering praise, whereas caregivers in Vanuatu use less formal practices, such as collaborating with children (Clegg et al., 2021). The current proposal builds on these views to suggest that development is not only shaped by other forms of culture but also that developmental milestones have important characteristics in common with other forms of culture, which means that knowledge from cultural psychology can inform scientific understanding of development and 
vice versa. Just as a person can be a member of a religious culture within a broader national culture, so too can a person experience age as similar to a kind of subculture in broader national cultures.

Despite these similarities between developmental milestones and other forms of culture, several differences exist as well. Perhaps most notably, many of the similarities between developmental milestones and cultures discussed above do not apply to infancy. Infants can be a group, but they do not engage in many of the social practices typically associated with cultures: They do not purposefully teach each other, lack a shared language that allows them to intentionally communicate with each other, and so on. Thus, frameworks from cultural psychology may be particularly helpful in understanding developmental milestones that occur after infancy. Furthermore, some work has discussed the importance of intergenerational transfer (Kitayama \& Uskul, 2011; Schonpflug, 2001; Senghas, 2003). According to this view, part of what defines a culture is the process by which older generations teach social practices to younger generations. Although individuals who are similarly situated to each other with regard to developmental milestones can teach social practices to each other (assuming these individuals are older than infancy), it is clearly impossible for intracultural learning to occur across generations. Using the lens of cultural psychology, any intergenerational learning would be akin to intercultural learning. Still, intracultural social learning can occur in particular milestones, with younger individuals learning from older individuals, as in the examples above, which suggest that the behavior of older adolescents may shape the behavior of their younger adolescent siblings (East, 1998; Harakeh et al., 2007). And despite these caveats, integrating developmental and cultural psychology to understand developmental milestones offers a number of novel insights for both areas of study, as outlined below.

\section{How Does Viewing Developmental Milestones Through the Lens of Culture Benefit the Study of Culture?}

Currently, cultural psychology and developmental psychology exist largely separately. As an exception to this general pattern, several scholars have investigated how culture shapes the cognition and behavior of children and their caregivers (e.g., Clegg et al., 2021; Greenfield et al., 2003; Schafer et al., 2015). However, it is rare for scholars to use frameworks from cultural psychology to understand developmental milestones themselves (e.g., to view developmental milestones as similar to other forms of culture). Such an approach would provide unique insight into questions that commonly arise in the cultural psychology literature, including questions regarding how cultures emerge and how culture shapes psychological processes.

\section{Questions concerning bow cultures emerge}

One of the most intriguing questions regarding culture concerns its origins (Boyd \& Richerson, 2005; D. Cohen, 2001). Where do different forms of culture come from, and how do they change over time? One way to approach this question is to examine new cultures that are just beginning to arise. A recent example is the emergence of Nicaraguan Sign Language among schoolchildren in the 1970s and 1980s (Senghas, 2003; Senghas et al., 2004). Before this period, deaf people in Nicaragua were not typically considered to form a cultural group; they often lived separately from each other and communicated with friends and relatives using idiosyncratic hand gestures. However, in 1977, 50 individuals came together in one program for deaf schoolchildren. Studying together created the conditions for the emergence of a new language as children created their own signs and taught these signs to others. Nicaraguan Sign Language has now been transmitted multiple times from one generation to the next and has evolved with each generation. These changes typically flow downward; for instance, the second cohort of signers developed new methods of expression that they transmitted to the third cohort, but the first cohort largely continued using the signs they themselves had developed.

The emergence of Nicaraguan Sign Language provided a natural experiment that clarified how new languages, and cultures, can form. It was all the more exciting to scholars because of how rare this type of phenomenon is. If one wants to study the emergence of culture, one cannot create the necessary conditions in a lab or randomly assign one group of people to form a culture and another group of people not to form a culture. Luck and patience are required.

This task becomes easier if one uses approaches from cultural psychology to understand developmental milestones. In this case, researchers are surrounded by people who are forming new cultures. For example, in developmental psychology, much research has focused on social changes that occur as children transition into adolescence. A common way to learn what behaviors one should perform as an adolescent is by observing one's peers. For instance, perceiving that peers are engaging in risky behaviors such as drinking alcohol or having unprotected sex increases the likelihood that the participant will engage in these same behaviors 
(e.g., Leung et al., 2014; van de Bongardt et al., 2014). Furthermore, people do not perceive all peers as equally informative; young adolescents are particularly likely to follow norms set by peers who are popular and slightly older than themselves (e.g., Chudek et al., 2011; East, 1998; Harakeh et al., 2007; Laursen et al., 2012). In other words, as an adolescent culture is forming, new arrivals (young adolescents) learn cultural norms from individuals who are members of the same culture but who have been in that culture longer (i.e., slightly older adolescents) and who are culturally connected (i.e., popular).

Developmental theories can do much to explain these patterns, but a cultural perspective offers an even more fully elaborated view by explaining why transmission of cultural knowledge often occurs between younger and older adolescents and not simply between adolescents and older community members. Developmentalists rightly point out that adolescence represents a time during which one's main developmental goal, especially in the United States, is to establish independence from one's parents (Erikson, 1956; Greenfield et al., 2003; Soenens et al., 2007). A developmental maturation perspective can explain why adolescents seek autonomy from their parents (e.g., as people develop, they seek independence), and a cultural psychology perspective can complement this view by explaining why adolescents seek to establish this autonomy in the particular way that they do-by turning largely to popular peers who are slightly older than themselves rather than people at other developmental stages who are not their parents. From the perspective of cultural psychology, it makes sense to learn about new developmental milestones from others who are firmly within the milestone in which the participant is a newcomer because these individuals may be best positioned to teach newcomers how to be a member of a culture. For instance, by observing older adolescents, younger adolescents can learn the cultural norms governing interactions with peers in their high school. These lessons would be difficult to learn from parents, who are unlikely to be familiar with this context. Psychologists focusing on the origins of culture have described such learning (i.e., imitating individuals slightly older than oneself) as one of the main adaptations that has allowed human beings to survive in diverse contexts (Boyd et al., 2011).

\section{Questions concerning bow culture shapes psychological processes}

Another common question in cultural psychology concerns how culture shapes psychological processes and the extent to which some processes may be culturally universal (Heine, 2016; Henrich et al., 2010). Work on developmental milestones can help address this question. One useful example here is moral realism, or the extent to which people perceive that morality is factlike. Someone who endorses moral realism may claim that moral questions have objectively correct answers and that if two people disagree about a moral claim, only one person can be right (Sayre-McCord, 1986). This is a useful example because moral realism is of great interest to both developmental and cultural psychologists, but the two literatures rarely intersect (but see Shweder et al., 1987, for work examining how people of different ages and from different cultures conceive of moral claims). Developmental psychology shows that moral realism decreases across age in the United States (Heiphetz \& Young, 2017; Wainryb et al., 2004), whereas cultural psychology shows that moral realism decreases with cross-cultural experience (Lu et al., 2017). If one views developmental milestones through the lens of cultural psychology, these findings can help explain one another. A maturation account may rely on cognitive changes to explain why moral realism decreases across age, and such cognitive changes certainly play some role in the observed decrease. However, a maturation account cannot explain why moral realism would also decrease with cross-cultural experience. Integrating developmental and cultural psychology can account for both findings simultaneously by suggesting that the more experience one has with other cultures (either by having gone through multiple developmental milestones or by traveling to other countries), the more likely one is to view morality as culturally relative or as more akin to an idiosyncratic preference than to an objective fact.

However, the two types of cross-cultural experiences referenced here differ somewhat from each other. One can develop national cross-cultural experience either by moving from one country to another or by living in one country and visiting others. In contrast, one cannot visit different developmental milestones; here, permanent immigration is the only option. How might such immigration, both in terms of cultural groups and in terms of developmental milestones, shape cognition?

Work in developmental and cultural psychology converges to suggest that one's original culture may leave an imprint even after one has left. Developmentally, adults retain many traces of childhood cognition on an implicit level despite the fact that they may override such responses on an explicit level. Much of this work has been conducted in the United States and has shown evidence of childhood intuitions among adults across a variety of domains. For instance, children report explicit preferences for members of their own groups and members of high-status groups (Aboud, 1988; Bigler et al., 1997; Heiphetz \& Young, 2019). Adults typically 
Heiphetz, Oishi

report more egalitarianism; however, strong preferences for in-groups and high-status groups emerge on implicit measures (Nosek et al., 2007). To give another example, children often report that human characteristics arise from innate, internal "essences" that are rooted in biology and remain stable over time (Gelman, 2003). Adults are far less likely than children to provide such a characterization explicitly, reporting instead that characteristics are sensitive to social factors (e.g., that shy people could be shy because of something they learned from others and that they could become less shy over time; Gelman et al., 2007; Heiphetz et al., 2017). However, on speeded reaction-time tasks, adults' responses look more similar to those reported by children (Eidson \& Coley, 2014). To give a third example, children often exhibit "intuitive theism" (Kelemen, 2004) and endorse creationist ideas even if they are raised in secular backgrounds (Evans, 2001). Secular adults disavow theism explicitly but show evidence of intuitive theism on speeded reaction-time measures (Heiphetz et al., 2015). One interpretation of all of these results is that childhood intuitions persist into adulthood. Adults can override these intuitions when they have sufficient resources (e.g., time, motivation). In the absence of such overriding, such as when adults must respond as quickly as possible, childlike intuitions emerge.

If one views developmental milestones through the lens of cultural psychology, these data suggest that moving from one culture to another does not eradicate ways of thinking common in the original culture. Instead, these ways of thinking may persist even if individuals come to explicitly adopt the cultural practices of their new group. Some initial evidence suggests that this does indeed occur, given that people who disaffiliate from religious groups show patterns of cognition and behavior that are more similar to people who are currently religiously affiliated than to people who have never been religiously affiliated (Van Tongeren et al., 2020). In other words, early religious affiliations, like early developmental stages, may continue to shape cognition even after people have left those affiliations or stages. Relatedly, the well-being of U.S. residents who claim ancestry from particular countries tends to be associated with the well-being reported in those countries (e.g., residents of Sweden and residents of the United States who report that their ancestors lived in Sweden both show relatively high levels of wellbeing; Rice \& Steele, 2004), and immigrants from countries that favor sons over daughters may themselves favor sons in some circumstances (Almond et al., 2013). Future research can more fully examine the experience of sojourners (people who move from one culture to another, including, in the current conceptualization, moving from one developmental milestone to another) using both cultural and developmental frameworks.

\section{How Does Viewing Developmental Milestones Through the Lens of Culture Benefit the Study of Development?}

As discussed above, viewing developmental milestones through the lens of cultural psychology benefits the study of culture. It also benefits the study of development by providing insight into conflict between individuals at different milestones and the ways in which developmental differences mirror cultural differences.

\section{Questions concerning conflict between individuals at different milestones}

Conflict between older and younger individuals is common in some contexts. For example, siblings-who are sometimes at different developmental milestones (e.g., a 10-year-old who is in late childhood and a 14-year-old adolescent)—often experience conflict during childhood (Brody, 1998; Song et al., 2016), and adults sometimes hold negative views of adolescents (Duffet et al., 1999; Protzko \& Schooler, 2019). Research on other forms of intercultural conflict can provide insight into the origins of conflict between people who are at different developmental milestones and offer suggestions for how to reduce it.

One relevant literature from work on culture centers on the contact hypothesis (Allport, 1954). According to this perspective, intercultural conflict arises in part because of social distance between groups and can be reduced when members of the conflicting cultures interact with each other (Berry, 2001; Ward \& Kennedy, 1993). The positive effects of intergroup contact are typically largest when contact occurs under certain conditions, such as when group members are of equal status and are working together toward a common goal (Pettigrew \& Tropp, 2006). Establishing these conditions across age groups may reduce conflict between people who are navigating different developmental milestones. For example, having an older sibling babysit a younger sibling may exacerbate conflict because this type of contact places the two siblings on unequal footing, with the older one controlling the younger one's outcomes. However, having two siblings work together toward a shared goal, such as cleaning their room together to earn a reward, may reduce conflict. Supporting predictions that interage contact can reduce conflict, prior work has shown that contact across age groups 
increases the positivity with which young people in the United States and England view older individuals (Caspi, 1984; Drury et al., 2016; Harwood et al., 2005). Although the older individuals in this prior work were adults, not siblings, future work can determine the extent to which interactions that occur under the conditions stipulated by the contact hypothesis promote positivity among individuals at a variety of developmental milestones.

Likewise, work on cross-cultural negotiation can inform conflict-reduction strategies between older and younger individuals. Negotiators from different cultures often use different strategies, which can make it difficult to engage in productive dialogue with their partners (Adair et al., 2001; Brett \& Thompson, 2016). They also often use different communication strategies, which can make it difficult for them to speak to each other (Von Glinow et al., 2004). However, trust is paramount to intercultural negotiations, and people who do not trust their negotiation partners typically fail to achieve their goals (Gunia et al., 2011). How can such trust be established? One line of work suggests that in cases in which verbal communication is difficult, it can be helpful for negotiators to rely on visual aids (Von Glinow et al., 2004). A separate body of work suggests that partners from different cultures can obtain better outcomes if at least one of the partners has experience with other cultures and, therefore, a deeper understanding of where their partner is "coming from" (Cao et al., 2014; Kern et al., 2012). These insights can inform dialogue between older and younger individuals, who also often employ different communication strategies. The suggestion to use visual aids may be particularly pertinent when parents are trying to talk with young children, who may be able to draw their emotions more easily than they can articulate them. Furthermore, older individuals can rely on their "bicultural experience" (i.e., their experience of having been younger themselves) to develop a better understanding of where younger people are coming from. Perspective-taking exercises in which older individuals remember what it was like for them to be the age of their conversation partner before engaging in cross-age conversations could promote more positive interaction.

\section{Questions concerning the ways in which developmental differences mirror cultural differences}

Developmental psychology knows a great deal about changes that occur as people age. Adopting a cultural framework to understand these changes can add additional insight to how cognition and behavior change across development.
As discussed above, a great deal of literature distinguishes cultures according to whether they are more collectivist or individualistic (e.g., Oishi \& Komiya, 2017; Oyserman \& Lee, 2008; Triandis, 1995). This difference emerges in diverse areas of human life. For instance, people in individualistic cultures tend to experience self-focused emotions, such as frustration and pride, more than people in collectivist cultures, who more often experience other-focused emotions, such as sympathy and shame (e.g., Kitayama et al., 2000; Scollon et al., 2004). In addition, people in individualistic cultures are more likely to emphasize consistent selves, seeing themselves as possessing certain characteristics across situations, whereas people in collectivist cultures are more likely to emphasize contextualized selves, seeing themselves differently depending on the context in which they are located at a particular time (Shweder \& Bourne, 1984; Suh, 2002). Even when the behaviors are similar, the underlying motivations may differ. For example, performing well in school could stem from a desire for personal gain in individualistic cultures and from a desire to reflect well on one's family in collectivist cultures (Markus \& Kitayama, 1991).

A different emphasis on collectivism compared with individualism also marks different developmental milestones. For instance, people in the United States typically experience more socially connected emotions as they age. A child who does not get what he or she wants may respond with frustration; the child may flatly contradict the other person (simply repeating the word "no"), yell, or storm out of the room (Noakes \& Rinaldi, 2006; Shantz, 1987). These behaviors would be unusual among adults, who may instead try to understand the other person's perspective and find a compromise. Developmental psychology typically explains these differences by referencing cognitive mechanisms such as language development (young children may lack the language to communicate with others during conflict; Church, 2016) and theory of mind (young children may lack the ability to understand the other person's point of view; Randell \& Peterson, 2009). Cultural psychology can provide a complementary framework to these maturation accounts for understanding this change. In other words, it may be the culture of being an older adultnot only an individual-level psychological change-that creates a more collectivist orientation as people age. They may have learned that they must rely on others to achieve many of their goals and, therefore, be more likely than children to respond to others' actions in collectivist ways. They may also recognize that their social networks are now smaller and less likely to change (Oishi et al., 2015; Yuki \& Schug, 2012), a process that could facilitate cooperation (i.e., working to resolve conflict productively rather than storming away 
in anger) if adults believe that they will not be able to readily acquire different social partners. Again, this cultural account is not intended to supplant the maturation account; it is clear that maturation plays a role in these age-related changes. However, adding the cultural account can provide a fuller understanding of what drives change across development.

As another example, cultures vary along a tightnesslooseness continuum (Gelfand et al., 2011; Harrington \& Gelfand, 2014). Tight cultures contain many social norms that are strongly enforced, and people face heavy sanctions for engaging in "improper" behaviors. In contrast, looser cultures contain fewer norms, and their norms are less tightly enforced. As with collectivism and individualism, cultural differences in tightness and looseness map on to different developmental milestones. Like adults in tight cultures, Western preschoolers readily enforce social norms (Koymen et al., 2014) and sanction individuals who violate norms (Heiphetz, 2017; McAuliffe et al., 2015). Furthermore, preschoolers in the United States are relatively intolerant of ambiguity; they often report that only one person can be right in a disagreement even when that disagreement concerns matters that older children and adults view as open to multiple correct viewpoints, such as personal preferences and some moral beliefs (Heiphetz \& Young, 2017; Wainryb et al., 2004). This feature of early childhood reflects tight cultures, which also typically promote the idea that there is only one correct answer to many questions (Gelfand et al., 2011).

Although maturation accounts can explain each of these changes individually, researchers do not typically study these developmental differences in one unifying framework. Viewing these differences in light of work on tight and loose cultures can lead to insights about why various processes, such as the propensity to punish people who violate norms and the propensity to say that only one person can be right in a disagreement, occur together in development. Furthermore, cultural psychology can provide a framework for understanding why preschoolers exhibit these patterns more than do older children and adults. Tight cultures tend to experience relatively more threat than loose cultures, and their tightness may be a response to this threat (Gelfand et al., 2011; Harrington \& Gelfand, 2014). Likewise, young children are vulnerable to a host of threats and must depend on others to stay safe. For instance, toddlers cannot obtain or prepare their own food or secure their own shelter, and they make a host of mistakes about which objects in their environment are safe; left to their own devices, they could consume things that are not safe to eat, fall from heights, electrocute themselves, and so on. As they get older, people develop a greater capacity to protect themselves. Perhaps as this occurs, they no longer need the protections of a tight culture and become more loose as a result. This perspective suggests that young children who live in especially threatening environments (e.g., abusive homes, countries at war) may show particularly strong similarities to individuals living in tight cultures (e.g., a greater desire to enforce rules and punish others).

\section{Conclusion}

As people grow, they navigate multiple developmental milestones, from infancy to toddlerhood to later childhood and beyond. In this article, we argue that cultural psychology offers a useful lens through which to view these changes. Integrating developmental and cultural psychology to understand developmental milestones benefits the study of culture by providing a unique lens through which to view questions that commonly arise in cultural psychology, including those concerning how cultures emerge and how they shape psychological processes. Integrating these two subdisciplines also benefits the study of development by providing a novel framework within which to understand topics relevant to developmental psychology, including conflict between people who are at different developmental milestones and age-related differences in cognition and behavior.

\section{Transparency}

Action Editor: Joshua Hicks

Editor: Laura A. King

Declaration of Conflicting Interests

The author(s) declared that there were no conflicts of interest with respect to the authorship or the publication of this article.

Funding

This project was supported by John Templeton Foundation Grants 61080 and 61808 to L. Heiphetz. This work was also supported (in part) by a Visiting Scholar award from the Russell Sage Foundation to L. Heiphetz. The opinions expressed in this publication are those of the authors and do not necessarily reflect the views of the John Templeton Foundation or the Russell Sage Foundation.

\section{Acknowledgments}

We thank Shinobu Kitayama and Redeate Wolle for their helpful comments.

\section{References}

Aboud, F. E. (1988). Children and prejudice. Blackwell. Adair, W. L., Okumura, T., \& Brett, J. M. (2001). Negotiation behavior when cultures collide: The United States and Japan. Journal of Applied Psychology, 86, 371-385. https:// doi.org/10.1037//0021-9010.86.3.371 
Adams, G., \& Markus, H. R. (2001). Culture as patterns: An alternative approach to the problem of reification. Culture E Psychology, 7, 283-296. https://doi.org/10.1177/ $1354067 X 0173002$

Allport, G. W. (1954). The nature of prejudice. AddisonWesley.

Almond, D., Edlund, L., \& Milligan, K. (2013). Son preference and the persistence of culture: Evidence from South and East Asian immigrants to Canada. Population and Development Review, 39, 75-95. https://doi.org/10.1111/ j.1728-4457.2013.00574.x

Berry, J. W. (2001). A psychology of immigration. Journal of Social Issues, 57, 615-631.

Bigler, R. S., Jones, L. C., \& Lobliner, D. B. (1997). Social categorization and the formation of intergroup attitudes in children. Child Development, 68, 530-543. https://doi .org/10.2307/1131676

Boyd, R., \& Richerson, P. J. (2005). The origin and evolution of cultures. Oxford University Press.

Boyd, R., Richerson, P. J., \& Henrich, J. (2011). The cultural niche: Why social learning is essential for human adaptation. Proceedings of the National Academy of Sciences, USA, 108, 10918-10925. https://doi.org/10.1073/ pnas. 1100290108

Brett, J., \& Thompson, L. (2016). Negotiation. Organizational Behavior and Human Decision Processes, 136, 68-79. https://doi.org/10.1016/j.obhdp.2016.06.003

Brody, G. H. (1998). Sibling relationship quality: Its causes and consequences. Annual Review of Psychology, 49, 1-24. https://doi.org/10.1146/annurev.psych.49.1.1

Brown, B. B., Lohr, M. J., \& McClenahan, E. L. (1986). Early adolescents' perceptions of peer pressure. The Journal of Early Adolescence, 6, 139-154. https://doi.org/10 $.1177 / 0272431686062005$

Bruner, J. S., Olver, R. R., \& Greenfield, P. M. (1966). Studies in cognitive growth. Wiley.

Callaghan, T., Rochat, P., Lillard, A., Claux, M. L., Odden, H., Itakura, S., Tapanya, S., \& Singh, S. (2005). Synchrony in the onset of mental-state reasoning: Evidence from five cultures. Psychological Science, 16, 378-384. https://doi .org/10.1111/j.0956-7976.2005.01544.x

Cao, J. Y., Galinsky, A. D., \& Maddux, W. W. (2014). Does travel broaden the mind? Breadth of foreign experiences increases generalized trust. Social Psychological and Personality Science, 5, 517-525. https://doi.org/ 10.1177/1948550613514456

Caspi, A. (1984). Contact hypothesis and inter-age attitudes: A field-study of cross-age contact. Social Psychology Quarterly, 47, 74-80. https://doi.org/10.2307/3033890

Chudek, M., Heller, S., Birch, S., \& Henrich, J. (2011). Prestige-biased cultural learning: Bystanders' differential attention to potential models influences children's learning. Evolution and Human Behavior, 33, 46-56. https:// doi.org/10.1016/j.evolhumbehav.2011.05.005

Church, A. (2016). Preference organization and peer disputes: How young children resolve conflict. Routledge.

Clegg, J. M., Wen, N. J., DeBaylo, P. H., Alcott, A., Keltner, E., \& Legare, C. H. (2021). Teaching through collaboration:
Flexibility and diversity in caregiver-child interaction across cultures. Child Development, 92(1), e56-e75. https://doi.org/10.1111/cdev.13443

Cohen, A. B. (2009). Many forms of culture. American Psychologist, 64, 194-204. https://doi.org/10.1037/a0015 308

Cohen, D. (2001). Cultural variation: Considerations and implications. Psychological Bulletin, 127, 451-471. https://doi .org/10.1037//0033-2909.127.4.451

Corriveau, K. H., Fusaro, M., \& Harris, P. L. (2009). Going with the flow: Preschoolers prefer nondissenters as informants. Psychological Science, 20, 372-377. https://doi .org/10.1111/j.1467-9280.2009.02291.x

Corsaro, W. A., \& Eder, D. (1990). Children's peer cultures. Annual Review of Sociology, 16, 197-220. https://doi .org/10.1146/annurev.so.16.080190.001213

Corsaro, W. A., \& Rizzo, T. A. (1990). Disputes in the peer culture of American and Italian nursery school children. In A. D. Grimshaw (Ed.), Conflict talk (pp. 21-66). Cambridge University Press.

DePaulo, B. M., \& Morris, W. L. (2006). The unrecognized stereotyping and discrimination against singles. Current Directions in Psychological Science, 15, 251-254. https:// doi.org/10.1111/j.1467-8721.2006.00446.x

Drury, L., Hutchison, P., \& Abrams, D. (2016). Direct and extended intergenerational contact and young people's attitudes towards older adults. British Journal of Social Psychology, 55, 522-543. https://doi.org/10.1111/ bjso. 12146

Duffet, A., Johnson, J., \& Farkas, S. (1999). Kids these days 99: What Americans really think about the next generation. Public Agenda.

East, P. L. (1998). Impact of adolescent childbearing on families and younger siblings: Effects that increase younger siblings' risk for early pregnancy. Applied Developmental Science, 2, 62-74. https://doi.org/10.1207/s15324 80xads0202_1

Eckert, P. (2003). Language and adolescent peer groups. Journal of Language and Social Psychology, 22, 112-118. https://doi.org/10.1177/0261927X02250063

Eidson, R. C., \& Coley, J. D. (2014). Not so fast: Reassessing gender essentialism in young adults. Journal of Cognition and Development, 15, 382-392. https://doi.org/10.1080/ 15248372.2013 .763810

Erikson, E. H. (1956). The problem of ego identity. Journal of the American Psychoanalytic Association, 4, 56-121. https://doi.org/10.1177/000306515600400104

Evans, E. M. (2001). Cognitive and contextual factors in the emergence of diverse belief systems: Creation versus evolution. Cognitive Psychology, 42, 217-266. https://doi .org/10.1006/cogp.2001.0749

Gelfand, M. J., Raver, J. L., Nishii, L., Leslie, L. M., Lun, J., Lim, B. C., Duan, L., Almaliach, A., Ang, S., Arnadottir, J., Aycan, Z., Boehnke, K., Boski, P., Cabecinhas, R., Chan, D., Chhokar, J., D'Amato, A., Ferrer, M., Fischlmayr, I. C., ... Yamaguchi, S. (2011). Differences between tight and loose cultures: A 33-nation study. Science, 332, 11001104. https://doi.org/10.1126/science.1197754 
Gelman, S. A. (2003). The essential child: Origins of essentialism in everyday thought. Oxford University Press.

Gelman, S. A., Heyman, G. D., \& Legare, C. H. (2007). Developmental changes in the coherence of essentialist beliefs about psychological characteristics. Child Development, 78, 757-774. https://doi.org/10.1111/j.1467-8624.2007 $.01031 . \mathrm{x}$

Georgas, J., Berry, J. W., van de Vijver, F. J. R., Kagitcibasi, C., \& Poortinga, Y. H. (Eds.). (2006). Families across cultures: A 30-nation psychological study. Cambridge University Press.

Gergely, G., Bekkering, H., \& Kiraly, I. (2002). Rational imitation in preverbal infants. Nature, 415, Article 755. https:// doi.org/10.1038/415755a

Goff, P. A., Jackson, M. C., Di Leone, B. A. L., Culotta, C. M., \& DiTomasso, N. A. (2014). The essence of innocence: Consequences of dehumanizing Black children. Journal of Personality and Social Psychology, 106, 526-545. https:// doi.org/10.1037/a0035663

Greenfield, P. M. (2013). The changing psychology of culture from 1800 through 2000. Psychological Science, 24, 1722-1731. https://doi.org/10.1177/0956797613479387

Greenfield, P. M., Keller, H., Fulgini, A., \& Maynard, A. (2003). Cultural pathways through universal development. Annual Review of Psychology, 54, 461-490. https:// doi.org/10.1146/annurev.psych.54.101601.145221

Gunia, B. C., Brett, J. M., Nandkeolyar, A. K., \& Kamdar, D. (2011). Paying a price: Culture, trust, and negotiation consequences. Journal of Applied Psychology, 96, 774-789. https://doi.org/10.1037/a0021986

Haidt, J. (2013). The righteous mind: Why good people are divided by politics and religion. Vintage Books.

Hamlin, J. K. (2013). Moral judgment and action in preverbal infants and toddlers: Evidence for an innate moral core. Current Directions in Psychological Science, 22, 186-193. https://doi.org/10.1177/0963721412470687

Harakeh, Z., Engels, R., Vermulst, A. A., De Vries, H., \& Scholte, R. H. J. (2007). The influence of best friends and siblings on adolescent smoking: A longitudinal study. Psychology \& Health, 22, 269-289. https://doi .org/10.1080/14768320600843218

Harrington, J. R., \& Gelfand, M. J. (2014). Tightness-looseness across the 50 United States. Proceedings of the National Academy of Sciences, USA, 111, 7990-7995. https://doi .org/10.1073/pnas.1317937111

Harwood, J., Hewstone, M., Paolini, S., \& Voci, A. (2005). Grandparent-grandchild contact and attitudes toward older adults: Moderator and mediator effects. Personality and Social Psychology Bulletin, 31, 393-406. https://doi .org/10.1177/0146167204271577

Heine, S. J. (2016). Cultural psychology. W.W. Norton.

Heiphetz, L. (2017). The development and importance of shared reality in the domains of opinion, morality, and religion. Current Opinion in Psychology, 23, 1-5. https:// doi.org/10.1016/j.copsyc.2017.11.002

Heiphetz, L., Gelman, S. A., \& Young, L. L. (2017). The perceived stability and biological basis of religious beliefs, factual beliefs, and opinions. Journal of Experimental Child Psychology, 156, 82-98. https://doi.org/10.1016/j .jecp.2016.11.015
Heiphetz, L., Spelke, E. S., \& Young, L. L. (2015). In the name of God: How children and adults judge agents who act for religious versus secular reasons. Cognition, 144, 134-149. https://doi.org/10.1016/j.cognition.2015.07.017

Heiphetz, L., \& Young, L. L. (2017). Can only one person be right? The development of objectivism and social preferences regarding widely shared and controversial moral beliefs. Cognition, 167, 78-90. https://doi.org/10.1016/j .cognition.2016.05.014

Heiphetz, L., \& Young, L. L. (2019). Children's and adults' emotional generosity toward members of different religious groups. American Behavioral Scientist, 63, 19101937. https://doi.org/10.1177/0002764219850870

Henrich, J., \& Gil-White, F. J. (2001). The evolution of prestige: Freely conferred deference as a mechanism for enhancing the benefits of cultural transmission. Evolution and Human Behavior, 22, 165-196. https://doi.org/10.1016/ S1090-5138(00)00071-4

Henrich, J., Heine, S. J., \& Norenzayan, A. (2010). The weirdest people in the world? Behavioral and Brain Sciences, 33, 61-83. https://doi.org/10.1017/S0140525X0999152X

Hofstede, G. (1980). Culture's consequences: International differences in work-related values. SAGE.

Hughes, D., Rodriguez, J., Smith, E. P., Johnson, D. J., Stevenson, H. C., \& Spicer, P. (2006). Parents' ethnicracial socialization practices: A review of research and directions for future study. Developmental Psychology, 42, 747-770. https://doi.org/10.1037/0012-1649.42.5.747

Kashima, Y. (2000). Recovering Bartlett's social psychology of cultural dynamics. European Journal of Social Psychology, 30, 383-403. https://doi.org/10.1002/(SICI)1099-0992 (200005/06)30:3<383::AID-EJSP996>3.0.CO;2-C

Katriel, T. (1988/1989). Haxlàfot: Rules and strategies in children's swapping exchanges. Research on Language and Social Interaction, 22, 157-178.

Kelemen, D. (2004). Are children "intuitive theists"? Reasoning about purpose and design in nature. Psychological Science, 15, 295-301. https://doi.org/10.1111/j.0956-7976.2004 $.00672 . x$

Kern, M. C., Lee, S., Aytug, Z. G., \& Brett, J. M. (2012). Bridging social distance in inter-cultural negotiations: "You" and the bi-cultural negotiator. International Journal of Conflict Management, 23, 173-191. https:// doi.org/10.1108/10444061211218294

Keysar, B., Lin, S. H., \& Barr, D. J. (2003). Limits on theory of mind use in adults. Cognition, 89, 25-41. https://doi .org/10.1016/S0010-0277(03)00064-7

Killen, M., Mulvey, K. L., Richardson, C., Jampol, N., \& Woodward, A. (2011). The accidental transgressor: Morally-relevant theory of mind. Cognition, 119, 197-215. https://doi.org/10.1016/j.cognition.2011.01.006

Kitayama, S., Markus, H. R., \& Kurokawa, M. (2000). Culture, emotion, and well-being: Good feelings in Japan and the United States. Cognition E Emotion, 14, 93-124. https:// doi.org/10.1080/026999300379003

Kitayama, S., \& Uskul, A. K. (2011). Culture, mind, and the brain: Current evidence and future directions. Annual Review of Psychology, 62, 419-449. https://doi .org/10.1146/annurev-psych-120709-145357 
Kohlberg, L., Levine, C., \& Hewer, A. (1983). Moral stages: A current formulation and a response to critics. Karger.

Koymen, B., Lieven, E., Engemann, D. A., Rakoczy, H., Warneken, F., \& Tomasello, M. (2014). Children's norm enforcement in their interactions with peers. Child Development, 85, 1108-1122. https://doi.org/10.1111/ cdev.12173

Kracke, B. (2002). The role of personality, parents and peers in adolescents' career exploration. Journal of Adolescence, 25, 19-30. https://doi.org/10.1006/jado.2001.0446

Kroeber, A. L., \& Kluckhohn, C. (1952). Culture: A critical review of concepts and definitions. Papers of the Peabody Museum of American Archeology and Ethnology, 47, 3217.

Laursen, B., Hafen, C. A., Kerr, M., \& Stattin, H. (2012). Friend influence over adolescent problem behaviors as a function of relative peer acceptance: To be liked is to be emulated. Journal of Abnormal Psychology, 121, 88-94. https://doi.org/10.1037/a0024707

Legare, C. H., \& Nielsen, M. (2015). Imitation and innovation: The dual engines of cultural learning. Trends in Cognitive Sciences, 19, 688-699. https://doi.org/10.1016/j .tics.2015.08.005

Leung, R. K., Toumbourou, J. W., \& Hemphill, S. A. (2014). The effect of peer influence and selection processes on adolescent alcohol use: A systematic review of longitudinal studies. Health Psychology Review, 8, 426-457. https:// doi.org/10.1080/17437199.2011.587961

Linklater, R. (Director). (2014). Boybood [Film]. IFC Productions. Linton, R. (1936). The study of man. Appleton-Century.

Lu, J. G., Quoidbach, J., Gino, F., Chakroff, A., Maddux, W. W., \& Galinsky, A. D. (2017). The dark side of going abroad: How broad foreign experiences increase immoral behavior. Journal of Personality and Social Psychology, 112, 1-16. https://doi.org/10.1037/pspa0000068

Markus, H. R., \& Kitayama, S. (1991). Culture and the self: Implications for cognition, emotion, and motivation. Psychological Review, 98, 224-253. https://doi.org/10 $.1037 / 0033-295 X .98 .2 .224$

Matsumoto, D. (1990). Cultural similarities and differences in display rules. Motivation and Emotion, 14, 195-214. https://doi.org/10.1007/BF00995569

McAuliffe, K., Jordan, J. J., \& Warneken, F. (2015). Costly third-party punishment in young children. Cognition, 134, 1-10. https://doi.org/10.1016/j.cognition.2014.08.013

Miller, S. A. (2009). Children's understanding of secondorder mental states. Psychological Bulletin, 135, 749-773. https://doi.org/10.1037/a0016854

Muthukrishna, M., Bell, A. V., Henrich, J., Curtin, C. M., Gedranovich, A., McInerney, J., \& Thue, B. (2020). Beyond western, educated, industrial, rich, and democratic (WEIRD) psychology: Measuring and mapping scales of cultural and psychological distance. Psychological Science, 31, 678-701. https://doi.org/10.1177/0956797620 916782

Nielsen, M., Haun, D., Kartner, J., \& Legare, C. H. (2017). The persistent sampling bias in developmental psychology: A call to action. Journal of Experimental Child Psychology, 162, 31-38. https://doi.org/10.1016/j.jecp.2017.04.017
Noakes, M. A., \& Rinaldi, C. M. (2006). Age and gender differences in peer conflict. Journal of Youth and Adolescence, 35, 881-891. https://doi.org/10.1007/s10964-006-9088-8

Nosek, B. A., Smyth, F. L., Hansen, J. J., Devos, T., Lindner, N. M., Ranganath, K. A., Smith, C. T., Olson, K. R., Chugh, D., Greenwald, A. G., \& Banaji, M. R. (2007). Pervasiveness and correlates of implicit attitudes and stereotypes. European Review of Social Psychology, 18, 36-88. https://doi.org/10.1080/10463280701489053

Oishi, S., \& Komiya, A. (2017). Natural disaster risk and collectivism. Journal of Cross-Cultural Psychology, 48, 12631270. https://doi.org/10.1177/0022022117719496

Oishi, S., Schug, J., Yuki, M., \& Axt, J. (2015). The psychology of residential and relational mobilities. Advances in Culture and Psychology, 5, 221-272.

Okonofua, J. A., \& Eberhardt, J. L. (2015). Two strikes: Race and the disciplining of young students. Psychological Science, 26, 617-624. https://doi.org/10.1177/0956797615570365

Onishi, K. H., \& Baillargeon, R. (2005). Do 15-month-old infants understand false beliefs? Science, 308, 255-258. https://doi.org/10.1126/science.1107621

Opie, L., \& Opie, P. (1969). Children's games in street and playground. Oxford University Press.

Oyserman, D. (2017). Culture three ways: Culture and subcultures within countries. Annual Review of Psychology, 68, 435-463. https://doi.org/10.1146/annurev-psych122414-033617

Oyserman, D., Gant, L., \& Ager, J. (1995). A socially contextualized model of African American identity: Possible selves and school persistence. Journal of Personality and Social Psychology, 69, 1216-1232. https://doi.org/10.1037/00223514.69.6.1216

Oyserman, D., \& Lee, S. W. S. (2008). Does culture influence what and how we think? Effects of priming individualism and collectivism. Psychological Bulletin, 134, 311-342. https://doi.org/10.1037/0033-2909.134.2.311

Perry, S. P., Skinner, A. L., \& Abaied, J. L. (2019). Bias awareness predicts color conscious racial socialization methods among White parents. Journal of Social Issues, 75(4), 1035-1056. https://doi.org/10.1111/josi.12348

Pettigrew, T. F., \& Tropp, L. R. (2006). A meta-analytic test of intergroup contact theory. Journal of Personality and Social Psychology, 90, 751-783. https://doi.org/10 .1037/0022-3514.90.5.751

Piaget, J., \& Inhelder, B. (1969). The psychology of the child. Basic Books

Protzko, J., \& Schooler, J. W. (2019). Kids these days: Why the youth of today seem lacking. Science Advances, 5, Article aav5916. https://doi.org/10.1126/sciadv.aav5916

Randell, A. C., \& Peterson, C. C. (2009). Affective qualities of sibling disputes, mothers' conflict attitudes, and children's theory of mind development. Social Development, 18, 857874. https://doi.org/10.1111/j.1467-9507.2008.00513.x

Rice, T. W., \& Steele, B. J. (2004). Subjective well-being and culture across time and space. Journal of CrossCultural Psychology, 35, 633-647. https://doi.org/10 $.1177 / 0022022104270107$

Sagner, A. (2017). Identity management and old age construction among Xhosa-speakers in urban South Africa: 
Complaint discourse revisited. In S. Makoni \& K. Stroeken (Eds.), Ageing in Africa: Sociolinguistic and anthropological approaches (pp. 43-65). Routledge.

Sayre-McCord, G. (1986). The many moral realisms. The Southern Journal of Philosophy, 24, 1-22. http://doi .org/10.1111/j.2041-6962.1986.tb01593.x

Schafer, M., Haun, D. B. M., \& Tomasello, M. (2015). Fair is not fair everywhere. Psychological Science, 26, 12521260. https://doi.org/10.1177/0956797615586188

Schlegel, A. (2000). The global spread of adolescent culture. In L. J. Crockett \& R. K. Silbereisen (Eds.), Negotiating adolescence in times of social change (pp. 71-88). Cambridge University Press.

Schmidt, M. F. H., Butler, L. P., Heinz, J., \& Tomasello, M. (2016). Young children see a single action and infer a social norm: Promiscuous normativity in 3-year-olds. Psychological Science, 27, 1360-1370. https://doi.org/ $10.1177 / 0956797616661182$

Schonpflug, U. (2001). Decision-making influence in the family: A comparison of Turkish families in Germany and in Turkey. Journal of Comparative Family Studies, 32, 219-230.

Schwartz, S. H. (1992). Universals in the content and structure of values: Theoretical advances and empirical tests in 20 countries. In M. P. Zanna (Ed.), Advances in experimental social psychology (Vol. 25, pp. 1-65). Academic Press. https://doi.org/10.1016/S0065-2601(08)60281-6

Schwartz, S. H., Cieciuch, J., Vecchione, M., Davidov, E., Fischer, R., Beierlein, C., Ramos, A., Verkasalo, M., Lonnqvist, J., Demirutku, K., Dirilen-Gamus, O., \& Konty, M. (2012). Refining the theory of basic individual values. Journal of Personality and Social Psychology, 103, 663-688. https://doi.org/10.1037/a0029393

Scollon, C. N., Diener, E., Oishi, S., \& Biswas-Diener, R. (2004). Emotions across cultures and methods. Journal of Cross-Cultural Psychology, 35, 304-326. https://doi .org/10.1177/0022022104264124

Scribner, S., \& Cole, M. (1973). Cognitive consequences of formal and informal education. Science, 182, 553-559. https://doi.org/10.1126/science.182.4112.553

Senghas, A. (2003). Intergenerational influence and ontogenetic development in the emergence of spatial grammar in Nicaraguan Sign Language. Cognitive Development, 18, 511-531. https://doi.org/10.1016/j.cogdev.2003 .09 .006

Senghas, A., Kita, S., \& Ozyurek, A. (2004). Children creating core properties of language: Evidence from an emerging sign language in Nicaragua. Science, 305, 1779-1782. https://doi.org/10.1126/science.1100199

Shantz, C. U. (1987). Conflicts between children. Child Development, 58, 283-305. https://doi.org/10.2307/1130507

Shweder, R. A., \& Bourne, E. J. (1984). Does the concept of the person vary cross-culturally? In R. A. Shweder \& R. A. LeVine (Eds.), Culture theory: Essays on mind, self, and emotion (pp. 158-199). Cambridge University Press.

Shweder, R. A., Mahapatra, M., \& Miller, J. G. (1987). Culture and moral development. In J. Kagan \& S. Lamb (Eds.), The emergence of morality in young children (pp. 1-83). The University of Chicago Press.
Snibbe, A. C., \& Markus, H. R. (2005). You can't always get what you want: Educational attainment, agency, and choice. Journal of Personality and Social Psychology, 88, 703-720. https://doi.org/10.1037/0022-3514.88.4.703

Soenens, B., Vansteenkiste, M., Lens, W., Luyckx, K., Goossens, L., Beyers, W., \& Ryan, R. M. (2007). Conceptualizing parental autonomy support: Adolescent perceptions of promotion of independence versus promotion of volitional functioning. Developmental Psychology, 43, 633646. https://doi.org/10.1037/0012-1649.43.3.633

Song, J. H., Volling, B. L., Lane, J. D., \& Wellman, H. M. (2016). Aggression, sibling antagonism, and theory of mind during the first year of siblinghood: A developmental cascade model. Child Development, 87, 1250-1263. https://doi.org/10.1111/cdev.12530

Stephens, N. M., Markus, H. R., \& Phillips, L. T. (2014). Social class culture cycles: How three gateway contexts shape selves and fuel inequality. Annual Review of Psychology, 65, 611-634. https://doi.org/10.1146/ annurev-psych-010213-115143

Stewart, S. M., Bond, M. H., Deeds, O., \& Chung, S. F. (1999). Intergenerational patterns of values and autonomy expectations in cultures of relatedness and separateness. Journal of Cross-Cultural Psychology, 30, 575-593. https:// doi.org/10.1177/0022022199030005002

Suh, E. M. (2002). Culture, identity consistency, and subjective well-being. Journal of Personality and Social Psychology, 83, 1378-1391. https://doi.org/10.1037//00223514.83.6.1378

Taras, V., Steel, P., \& Kirkman, B. L. (2016). Does country equate with culture? Beyond geography in the search for cultural boundaries. Management International Review, 56, 455-487. https://doi.org/10.1007/s11575-016-0283-x

Thompson, R., Yuki, M., Talhelm, T., Schug, J., Kito, M., Ayanian, A. H., Becker, J. C., Becker, M., Chiu, C., Choi, H., Ferreira, C. M., Fulop, M., Gul, P., Houghton-Illera, A. M., Joasoo, M., Jong, J., Kavanagh, C. M., Khutkyy, D., Manzi, C., . . . Visserman, M. L. (2018). Relational mobility predicts social behaviors in 39 countries and is tied to historical farming and threat. Proceedings of the National Academy of Sciences, USA, 115, 7521-7526. https://doi .org/10.1073/pnas.1713191115

Tottenham, N. (2020). Early adversity and the neotenous human brain. Biological Psychiatry, 87, 350-358. https:// doi.org/10.1016/j.biopsych.2019/06.018

Triandis, H. C. (1995). Individualism and collectivism. Avalon.

Twenge, J. M., Campbell, W. K., \& Freeman, E. C. (2012). Generational differences in young adults' life goals, concern for others, and civil orientation, 1966-2009. Journal of Personality and Social Psychology, 102, 1045-1062. https://doi.org/10.1037/a0027408

van de Bongardt, D., Reitz, E., Sandfort, T., \& Dekovic, M. (2014). A meta-analysis of the relations between three types of peer norms and adolescent sexual behavior. Personality and Social Psychology Review, 19, 203-234. https://doi.org/10.1177/1088868314544223

van Schaik, C. P. (2010). Social learning and culture in animals. In P. Kappeler (Ed.), Animal behaviour: Evolution and mechanisms (pp. 623-654). Springer. 
Vandello, J. A., \& Cohen, D. (1999). Patterns of individualism and collectivism across the United States. Journal of Personality and Social Psychology, 77, 279-292. https:// doi.org/10.1037/0022-3514.77.2.279

Van Tongeren, D. R., DeWall, C. N., Chen, Z., Sibley, C. G., \& Bulbulia, J. (2020). Religious residue: Cross-cultural evidence that religious psychology and behavior persist following deidentification. Journal of Personality and Social Psychology. Advance online publication. https:// doi.org/10.1037/pspp0000288

Varnum, M. E. W., \& Grossmann, I. (2017). Cultural change: The how and the why. Psychological Science, 12, 956972. https://doi.org/10.1177/1745691617699971

Von Glinow, M. A., Shapiro, D. L., \& Brett, J. M. (2004). Can we talk, and should we? Managing emotional conflict in multicultural teams. Academy of Management Review, 29, 578-592.

Wainryb, C., Shaw, L. A., Langley, M., Cottam, K., \& Lewis, R. (2004). Children's thinking about diversity of belief in the early school years: Judgments of relativism, tolerance, and disagreeing persons. Child Development, 75, 687-703. https://doi.org/10.1111/j.1467-8624.2004.00701.x
Ward, C., \& Kennedy, A. (1993). Psychological and sociocultural adjustment during cross-cultural transitions: A comparison of secondary students overseas and at home. International Journal of Psychology, 28, 129-147. https:// doi.org/10.1080/00207599308247181

Wellman, H. M., Cross, D., \& Watson, J. (2001). Meta-analysis of theory-of-mind development: The truth about false belief. Child Development, 72, 655-684. https://doi .org/10.1111/1467-8624.00304

Wimmer, H., \& Perner, J. (1983). Beliefs about beliefs: Representation and constraining function of wrong beliefs in young children's understanding of deception. Cognition, 13, 103-128. https://doi.org/10.1016/0010-0277(83)90004-5

Wood, D., \& O'Malley, C. (1996). Collaborative learning between peers. Educational Psychology in Practice, 11, 4-9. https://doi.org/10.1080/0266736960110402

Yuki, M., \& Schug, J. (2012). Relational mobility: A socioecological approach to personal relationships. In $\mathrm{O}$. Gillath, G. E. Adams, \& A. D. Kunkel (Eds.), New directions in close relationships: Integrating across disciplines and theoretical approaches (pp. 137-151). American Psychological Association. 